\title{
A EDUCAÇÃO PERSONALISTA E A TRANSFORMAÇÃO DA SOCIEDADE: CONTRIBUIÇÕES DE LOUIS ALTHUSSER E EMMANUEL MOUNIER
}

\author{
Antonio Glauton Varela Rocha ${ }^{1}$ \\ Universidade Federal do Ceará (UFC) \\ id https://orcid.org/0000-0002-3735-7447
}

\begin{abstract}
RESUMO:
Este artigo apresenta a proposta de Emmanuel Mounier e a crítica de Louis Althusser em relação à educação capitalista e articula um contato entre essas duas posições. Não é um contato que tem como objetivo um consenso entre os dois autores, mas que procura apontar como podemos aliar a consciência do perigo de alienação na educação com a esperança que a educação pode representar se for desenvolvida com os devidos cuidados (para evitar o perigo citado) e tendo em vista uma concepção integral da pessoa, o que se alcança se a educação é entendida não só como instrução, mas também como formação. Com este enfoque é possível que a pessoa cresça não apenas numa instrução para a profissão, mas numa formação para a liberdade.
\end{abstract}

PALAVRAS CHAVES: Educação; Formação; Ideologia; Pessoa.

\section{THE PERSONALIST EDUCATION AND THE CHANGING OF SOCIETY: CONTRIBUTIONS OF LOUIS ALTHUSSER AND EMMANUEL MOUNIER}

\begin{abstract}
:
This article presents the proposal of Emmanuel Mounier and criticism of Louis Althusser in relation to capitalist education and articulates a contact between these two positions. Such it is not one which aims a consensus for the two authors, but one which seeks to point out how we can combine the

${ }^{1}$ Doutorando em Filosofia pela Universidade Federal do Ceará - UFC, professor e coordenador do Curso de Bacharelado em Filosofia da Faculdade Católica Rainha do Sertão - FCRS. E-mail: glautonvarela@yahoo.com.br
\end{abstract}


alienation danger's awareness in education along with the hope the education itself must represents if it is developed with due care (just to avoid the mentioned danger), having in order an integral concept of person, what it is achieved whether education may be understood not only as instruction, but also as formation. With this approach it is possible the person grows not only inside an instruction to some profession, but indeed inside a true formation to liberty.

KEY WORDS: Education; Formation; Ideology; Person.

\section{Introdução}

O título do artigo já antecipa um pouco sobre suas orientações. Notamos que dois pensadores em especial serão tematizados neste texto, mas um detalhe do título nos permite ver qual deles terá mais destaque: o adjetivo personalista que vem logo após a palavra educação. Veremos com mais detalhes o pensamento de Emmanuel Mounier - fundador e articulador do movimento personalista contemporâneo - sobre a educação. Neste contexto, a análise da educação capitalista feita por Louis Althusser pode nos dá bons elementos para explicitar a proposta personalista.

Mounier descobriu cedo que a filosofia era sua vocação. Começou os estudos ainda na sua cidade natal, Grenoble, sob a orientação de Jacques Chevalier. Quando concluiu esta etapa foi para Paris, um momento muito importante em sua vida, muito mais pelos contatos que teve com grande numero de pensadores e pela participação nos grupos de discussão que lá existiam do que pelo ingresso no doutorado. Depois do início dos estudos na Sorbonne, Mounier logo começa a se incomodar com a perspectiva de ensino que a instituição praticava: uma filosofia profundamente desligada das realidades concretas das pessoas. A estada em Paris e a participação nos grupos de discussão mostraram a Mounier uma crise de civilização que assolava a Europa e que certamente não era um "privilégio" apenas do velho continente. Os jovens pensadores percebiam cada vez mais a necessidade de se fazer algo em relação a esta crise, e Mounier via na postura desinteressada e indiferente da Sorbonne o quanto a educação que lá se praticava era alienante. Não suportando esta situação, decide abandonar o doutorado - e a carreira acadêmica que se desenhava promissora - para viver uma filosofia que não fosse alheia ao sofrimento dos homens, nas suas palavras: uma filosofia engajada.

Mounier partiu da situação concreta das pessoas para depois fazer uma teoria da pessoa. Sua preocupação com o mundo concreto fez com que sua antropologia fosse diretamente vinculada às consequências éticas e políticas. Sua antropologia, deste modo, era intrinsecamente ligada a um compromisso: a construção de um mundo mais justo. Um momento crucial desta transformação passava pela educação, não apenas uma educação que 
ensinasse as pessoas como fazer coisas, mas que as fizesse compreender a si mesmas, sobre o lugar de cada um na sociedade, uma educação preocupada com o desenvolvimento integral da pessoa. A grande preocupação de Mounier quando falava em educação, era como fazer para que ela representasse um equilíbrio entre a instrução e a formação, pois desta forma estaríamos mais preparados para enfrentar as distorções no ato de educar, como as que foram denunciadas por Althusser.

\section{Louis Althusser e a crítica à educação como manutenção do status quo}

A fala de Louis Althusser sobre a educação na obra Ideologia $e$ aparelhos ideológicos do Estado evidencia uma forma pela qual a educação é manipulada e se torna um mecanismo de alienação e manutenção de um sistema social opressor. Althusser é um filósofo marxista, e de tal modo a crítica ao capitalismo é uma chave de leitura importante para entendermos a denúncia feita por ele. Para Althusser, o capitalismo precisa que a sociedade permaneça como está: configurada de tal modo que a opressão dos pobres continue a sustentar os privilégios da classe dominante. A educação seria usada pelo capitalismo como um instrumento de manutenção deste status quo (Cf. LUCKESI, 2005, p. 44).

Althusser parte da análise de Karl Marx a respeito da reprodução dos meios de produção. Marx nos recorda que a produção, buscada pelo capitalista como fonte do seu lucro, não pode continuar ou se reproduzir se não age para assegurar a continuidade, manutenção e renovação dos meios de produção (matérias-primas, edifícios, maquinaria, funcionários, etc), especialmente a força de trabalho (os funcionários).

A forma de a empresa reproduzir a força de trabalho é viabilizando os meios materiais para que esta força possa se conservar e se reproduzir; este meio é o salário (Cf. ALTHUSSER, 1985, p. 56). O pagamento do salário é o meio material que a empresa utiliza em vista da conservação biológica do trabalhador (meramente o suficiente para que o trabalhador tenha a força necessária para retornar ao trabalho e continuar a produção nos dias seguintes, e também para o trabalhador se reproduzir e produzir um futuro operário). No entanto, o salário não é suficiente para reproduzir integralmente a força de trabalho, pois o trabalhador não precisa apenas estar vivo, precisar também ter um conjunto de competências e habilidades que o tornem apto para exercer corretamente a sua função (Cf. ALTHUSSER, 1985, p. 57).

A qualificação do trabalhador obedece a um determinado quadro de necessidades do sistema capitalista e se desenvolve especialmente no sistema educativo (Cf. ALTHUSSER, 1985, p. 57). A escola, neste contexto, ensina a ler, a escrever, a contar, entre outras técnicas, além de certa "cultura científica" e literária. São saberes utilizáveis nos distintos 
cargos, constituídos a partir daquele quadro de necessidades acima indicado. Em suma, aprendem-se habilidades e técnicas.

Além destas habilidades e técnicas é preciso aprender também certas regras de convivência e de comportamento segundo o posto que se ocupa (ou que se vai ocupar) (Cf. ALTHUSSER, 1985, p. 58). Deste modo é preciso aprender a respeitar quem alcança patamares mais altos. Os saberes mais aprofundados (que vão além de simples habilidades) geralmente incidem na vida dos futuros capitalistas, pois estes precisam estar aptos para mandar e manter a ordem vigente. Em síntese: constituído deste modo, o sistema educativo converte-se num instrumento importantíssimo para a manutenção da dominação de classes (Cf. ALTHUSSER, 1985, p. 58).

Destaquemos então os dois elementos mais importantes que acima foram descritos: por um lado é preciso reproduzir um conjunto de habilidades técnicas necessárias ao trabalho dos que não possuem o capital, por outro lado também é preciso reproduzir um conjunto de boas regras que na verdade são regras de submissão à ordem vigente $^{2}$, preparando o trabalhador para obedecer e o capitalista para dominar (submissão à ideologia e domínio da prática desta ideologia).

Vemos então que Althusser destaca aspectos muito negativos quanto ao papel da educação na sociedade capitalista (Cf. ALTHUSSER, 1985, p. 79). A educação por ele descrita é sem dúvida um tipo de perspectiva educacional alienante e que pouco tem a contribuir para emancipação humana. Temos uma ótima descrição sobre como a educação também pode ser instrumento de alienação quando não tem por base a preocupação com a emancipação humana. Após a denúncia feita por Althusser, na sequência do texto tentaremos ver uma outra perspectiva de educação (não sob a orientação dos interesses capitalistas), onde a emancipação e a personalização das pessoas estariam em primeiro plano. $\mathrm{O}$ autor que tomaremos como base neste segundo momento será Emmanuel Mounier.

A orientação que a educação recebe depende do tipo de antropologia que a precede. Emmanuel Mounier defende a compreensão da educação dentro do contexto de uma antropologia em que o homem não é apenas matéria, mas também espírito. A axiologia possui em sua proposta um papel

\footnotetext{
${ }^{2}$ Esta visão de educação profundamente ligada ao processo de instrumentalização da racionalidade denunciado por outros autores de tradição marxista, em especial no contexto da Teoria Crítica. Adorno e Horkheimer denunciavam que a razão não apenas está apta a explica como as coisas são, mas como elas devem ser, pois o que as coisas devem ser faz parte do que elas são. Quando a razão é reduzida a mero meio de explicação de como o mundo é, ela perde seu caráter crítico e se torna apenas um instrumento, e certamente fica muito mais vulnerável às manipulações. De modo análogo, quando a educação se torna apenas um mecanismo de explicação de como as coisas são, ela se converte em mero instrumento, sem qualquer criticidade e sem possibilidade de enfrentamento dos riscos da manipulação. Neste contexto, ela é facilmente utilizada como instrumento para manutenção do status quo. Sobre esta discussão a partir da visão da Teoria Crítica, ver: (NOBRE, 2004, p. 28-33).
} 
decisivo, e onde a questão dos valores se torna fundamental a educação também se torna ainda mais fundamental (ao menos se a compreendemos sob o sentido mais amplo, em que a emancipação é uma questão importante para o sistema educativo).

\section{O papel da educação no personalismo de Emmanuel Mounier}

A educação possui grande importância no pensamento de Mounier. A valorização da educação foi tão significativa em sua filosofia que muitos autores consideraram o personalismo mounieriano como sendo, antes de tudo, um projeto pedagógico. Para Ricoeur, por exemplo, a obra de Mounier deve ser compreendida como um grande ensaio educativo, uma pedagogia da vida comunitária destinada à renovação da pessoa (Cf. LOPEZ, 1989, p. 201). Para Mounier, a educação só poderá contribuir para transformação da sociedade se tem em vista a pessoa na sua integralidade, não apenas uma das facetas de sua vida - como a função a desempenhar na sociedade (profissão) -; deve também estar aberta à historicidade essencial do ser humano, o que implica o contato e a referência à realidade concreta das pessoas. Não era esse tipo de educação que Mounier via se desenvolvendo em seu tempo. Mounier, de fato, foi um grande crítico dos sistemas educativos de sua época, como podemos perceber nos trechos a seguir:

A educação que hoje em dia é distribuída prepara o pior possível para uma tal cultura da ação. A universidade distribui uma ciência formativa que conduz ao dogmatismo ideológico ou, por reação, à ironia estéril. Os educadores espirituais conduzem na maior parte dos casos a formação para $o$ escrúpulo ou para o caso de consciência, em vez de a encaminharem para o culto da decisão. É todo um clima a modificar, se não quisermos ver mais os nossos intelectuais a dar exemplo da cegueira e, os mais conscienciosos, da covardia (MOUNIER, 1976, p. 167).

Pode-se dizer da nossa educação que ela era em larga escala um 'massacre dos inocentes': desconhecendo a personalidade da criança como tal, impondo-lhe um resumo das perspectivas do adulto, as desigualdades sociais forjadas pelos adultos, substituindo o discernimento dos caracteres e das vocações pelo formalismo autoritário do saber (MOUNIER, 1976, p. 200).

Mounier defendia que o fim da educação “... não consiste em fazer, mas em despertar pessoas. Por definição, uma pessoa suscita-se por apelos, não se fabrica domesticando" (MOUNIER, 1976, p. 200). O tom socrático que se observa nesta afirmação não está aqui por acaso. Já foi dito que 
Mounier é o mais socrático dos pensadores do século $\mathrm{XX}^{3}$ (Cf. ROCHA, 2006 , p. 184). Nunca foi sua pretensão deixar um sistema pronto, mas apontar para certa maneira de pensar e agir, de relacionar as ideias e a vida concreta. Mais que formar seguidores, ele quis fomentar apelos que atingissem as pessoas e as fizessem despertar por elas mesmas. Para Mounier a educação não pode partir de outra perspectiva, “... sua missão é a de despertar pessoas capazes de viver e de assumir posições como pessoas" (MOUNIER, 1967, p. 133).

Mounier viveu num tempo de crise e para ele era preciso mais que falas e teorias para que a sociedade enfrentasse as dificuldades em que estava mergulhada. Esse desejo de mudança social e esta percepção da urgência da mesma eram elementos que ele compartilhava com Marx, no entanto, ele não tinha como aceitar que verdadeiras mudanças acontecessem se apenas os aspectos econômicos e políticos fossem observados (a proposta dos materialistas), assim como não se contentava com a ênfase exclusiva nos aspectos morais da vida humana (como era a proposta dos espiritualistas). Para Mounier a revolução social precisava ser ao mesmo tempo econômica e moral, material e espiritual, pois se o homem é matéria e espírito nenhuma mudança significativa ocorreria na sociedade se o esforço de mudança se concentrasse em apenas um destes elementos.

A revolução necessária só se encaminha para uma solução real da crise de civilização quando se apoia numa mudança de mentalidade dos sujeitos. Educação e revolução se implicam mutuamente para que aquela não seja um simples ajuste das pessoas a uma situação dada, ou o desinteresse espiritualista das condições por transformar, e para que esta não seja uma simples mudança no externo da história na qual as aspirações e exigências da pessoa são novamente burladas (LOPEZ, 1989, p. 200).

Certamente Mounier deve a Marx a percepção de que é preciso estar atento às necessidades materiais do homem e às determinações materiais que o homem possui. Por isso a educação que Mounier defende pressupõe a formação (especialmente em vista da liberdade) e também a instrução. É importante destacar aqui que formação de que Mounier fala não está em função apenas do aprimoramento moral da pessoa, mas também em vista de uma maior atuação e participação no campo político ou qualquer área que diga respeito à vida concreta das pessoas.

\section{Educação como instrução e formação}

\footnotetext{
${ }^{3}$ Sobre a relação entre Mounier e Sócrates, ver também a introdução da obra Mounier: o engajamento político, de Guy Coq (COQ, 2012, p. 20).
} 
Mounier distinguia duas dimensões fundamentais no processo educativo: a instrução e a formação. Em linhas gerais, podemos dizer que a instrução diz respeito à transmissão de conhecimentos técnicos necessários ao desempenho de uma profissão; já a formação diz respeito ao suscitar nas pessoas a capacidade de pensar criticamente e também diz respeito à reflexão sobre a dimensão dos valores na vida humana.

Para Mounier é fundamental a construção de uma visão de educação que tenha por base a proposta de equilíbrio entre ambas as dimensões (instrução e formação). Somente com esta base a educação realmente poderá ter em vista o ser humano por completo (em sua integralidade) e prepara-lo para uma vida como pessoa. Esta visão de educação nasce de sua visão sobre o ser humano e sua relação com o mundo. O ser humano é materialidade, tem necessidades materiais, e a educação precisa estar atenta a estas necessidades, por isso Mounier, em nenhum momento, busca negar que “... a posse de uma profissão é necessária a esse mínimo de liberdade material sem a qual toda vida pessoal é sufocada...", porém “... a preparação profissional, a formação técnica e funcional não poderiam ser o centro ou a mola real da obra educativa" (MOUNIER, 1967, p. 133). Para Mounier, além da condição de materialidade, o ser humano é também um ser de criatividade, de liberdade, de espiritualidade, por isso é preciso que o processo educativo tenha sempre em conta a necessidade de preparar as pessoas para atender estas outras necessidades, e é aqui que entra o caráter formativo da educação.

Dizer que a educação precisa ser construída sobre uma base de equilíbrio entre instrução e formação significa dizer que é preciso uma educação que prepare as pessoas para ter o seu sustento, para que saibam as técnicas de atuação de sua profissão com eficácia, mas também que é preciso uma educação que prepare as pessoas para pensar, que as ensine a ser questionadoras, que as prepare para se defender das manipulações (que ameaçam a todos aqueles que não se dedicam a pensar antes de agir, ou não refletem sobre as informações que recebem), e que lhes ensine o senso de comunidade, respeito e tolerância necessários a uma vida em sociedade.

Mounier enfrentou diretamente o problema de uma educação que é reduzida à instrução. Ele percebeu que esta educação estava muitas vezes a serviço de uma ideologia dominante, mas entendeu que o problema não era apenas o de relações sociais ou econômicas injustas, mas também o da construção de uma compreensão distorcida a respeito do homem. Por isso a educação precisa partir de uma compreensão equilibrada do ser humano em suas dimensões, daí podermos dizer que Mounier propõe uma pedagogia integradora, que devolve ao homem o gozo de um sentido completo de seu próprio ser e da história (Cf. LOPEZ, 1989, p. 202).

Para Mounier, uma escola não pode se limitar a oferecer instrução, conhecimentos livrescos disfarçados de cultura, mas isto não quer dizer que Mounier retira do processo educativo o ensino de conhecimentos técnicos 
destinados ao desempenho das mais variadas profissões na sociedade (Cf. ROCHA, 2013, p. 161). Mounier, em nenhum momento, nega que possui uma profissão é necessário, pois é a base para que todos tenhamos uma mínima segurança material. O que é necessário é uma profunda reestruturação dos sistemas educativos de modo a elaborarem seus programas baseados na pessoa em sua integralidade, e não apenas pensando em oferecer-lhe condições técnicas para exercerem uma função social ou uma educação voltada para tornar o educando capaz de se conformar com a situação vigente.

O fundo do problema, pensa ele [Mounier], é que as instituições educativas se orientam mais que a suscitar pessoas, a satisfazer umas necessidades sociais: a qualificação para o exercício de tal e qual papel e, em definitivo, a criar um cidadão adaptado aos moldes e pautas vigentes (LOPEZ, 1989, p. 207).

Mounier sempre destacava que era preciso pensar uma educação para a liberdade, e isto ele demonstrava não apenas nos livros, mas também em sua atuação em sala de aula. Diferente de seus colegas professores, Mounier se incomodava com o silêncio dos alunos em sala. Ele queria ver questionamentos, e estimulava os alunos a se posicionarem. Como podemos ver neste depoimento de um de suas alunas:

Contrariamente aos outros professores que procuravam fazer reinar silêncio numa classe turbulenta, ele não suportava a nossa calma e nos estimulava a falar. Ele gostava das interrupções, das questões, das objeções: ele queria que fôssemos mais ativos (LORENZON, 1996, p. 64).

Certamente uma postura bem incomum para a época. Mounier buscava despertar energia, suscitar autoconsciência e provocar decisões (Cf. LOPEZ, 1989, p. 202). O objetivo era preparar os alunos para serem pessoas plenas, não apenas bons matemáticos ou escritores, e essa plenificação da pessoa passa pela capacidade de se posicionar, de sair do anonimato (que é o fermento da massa e de uma vida inautêntica). Vale lembrar que Mounier sempre falava da liberdade ao lado de outro importante atributo, a responsabilidade (Cf. ROCHA, 2013, p. 160).

Esse testemunho nos remete ao fato de que uma educação que prime por certos valores prévios (no caso, a liberdade, a responsabilidade, a iniciativa, a autoposse, a criticidade, para citar alguns) não precisa e nem deve ser dogmática e impositiva. Primeiro porque o foco em tais valores já é um grande passo para extirpar qualquer sombra de postura dogmática e impositiva e, segundo, porque a forma como Mounier buscava apontar para tais valores, longe de ser uma domesticação, era um exercício de criticidade e liberdade (Cf. ROCHA, 2013, p. 160-161). Feito estes esclarecimentos, 
podemos entender melhor porque para Mounier a educação não pode ser neutra.

\begin{abstract}
Numa cidade que o tome [o personalismo] por base, nenhuma escola pode justificar ou cobrir a exploração do homem pelo homem, a prevalência do conformismo social ou da razão de Estado, a desigualdade moral e cívica das raças ou das classes, superioridade, na vida privada ou pública, da mentira sobre a verdade, do instinto sobre o amor e o desinteresse. É neste sentido que nós dizemos que a escola laica, ela mesma não pode ser não deve ser educativamente neutra (...). Neutra, é-o ela somente, nesta perspectiva, na medida em que não propõe, nem mesmo implicitamente, preferência por nenhum sistema de valores objetivos para lá desta formação da pessoa (MOUNIER, 1967, p.137).
\end{abstract}

Por fim, é preciso ainda destacar, sobre o tema da educação, quer seja exercida na escola ou no seio familiar, que é preciso distanciar a educação de dois perigos graves. Em primeiro lugar, é preciso lembrar que não se pode entender a educação no âmbito personalista, apenas como processo de transformação interior. De fato, essa perspectiva tem de estar presente numa pedagogia de inspiração personalista, mas ela deve sempre estar atrelada à perspectiva de uma transformação externa, a revolução estrutural da sociedade. Muitos leitores querem ver na obra de Mounier apenas o processo de valorização da transformação moral e o papel dos valores, mas acabam traindo profundamente o pensamento de Mounier quando desligam essas questões do necessário compromisso social; sem esse compromisso, não estamos falando de uma educação de inspiração personalista (Cf. LOPEZ, 1989, p. 203). Em segundo lugar - mas ainda insistindo na questão da exterioridade -, devemos lembrar que se, por um lado, é verdade que a educação é um processo de libertação e emancipação, por outro lado, não pode ser compreendida apenas como emancipação do indivíduo. "Educar o homem é provocar nele o encontro com a comunidade" (LOPEZ, 1989, p. 206). Sem essa preocupação, cairíamos no mesmo erro dos renascentistas: passaram por um processo de libertação do homem em relação a um sistema opressor, mas acabaram presos às amarras do individualismo (Cf. LOPEZ, 1989, p. 206). Se a educação é um processo que deve ter em vista a pessoa em sua integralidade, não poderia então esquecer seu aspecto comunitário. Pensada e trabalhada numa perspectiva personalista, portanto, “... a educação só personaliza quando é educação para a comunhão” (LOPEZ, 1989, p. 206).

\title{
Considerações finais
}

A educação é sempre um tema importante quando se está em debate a transformação ou melhoria da vida em sociedade. No entanto, a 
importância que ela pode representar neste processo pode levar a consideração de que a educação é um processo fora do mundo, que o observa e pacientemente traça as estratégias para corrigir os problemas do homem e da sociedade. Althusser e Mounier são pensadores que mostram a educação como um processo humano, que está emaranhado na condição humana, e é passível dos mesmos condicionamentos que qualquer pessoa está sujeito, exatamente porque não é um processo para além do humano. Se está emaranhada na condição humana, está sujeita igualmente aos riscos de alienação e pior, pode contribuir para manutenção e reprodução da alienação. Para Althusser este foi o destino da educação em seu contato com o capitalismo, e de tal modo, caminhou para o oposto do que normalmente esperamos de um processo educacional. A partir de Mounier, e sua inspiração de pensar a educação sempre como equilíbrio entre instrução e formação, podemos perceber um caminho em que o processo educativo ganha muito em potencial de transformação da sociedade, não apenas em seus aspectos materiais, mas também na ordem dos valores.

Diante disto, podemos afirmar a importância de sempre estarmos atentos para os objetivos que estão em jogo no processo educativo, pois estes objetivos podem influencia diretamente no futuro da pessoa humana, e para que este futuro seja promissor temos que ir além da percepção do ser humano com apenas um simples manipulador da natureza, é preciso mais do que nunca pensar uma educação para a liberdade. Mounier aponta o equilíbrio na compreensão do homem, como ser igualmente material e espiritual, e a associação da educação a esta visão equilíbrio, como um caminho de resistência aos riscos de alienação que rondam o ser humano e também a ação pedagógica. Ao conceber o educar como equilíbrio entre o instruir e o formar, Mounier resgata o sentido crítico da educação, sentido que permite a formação de pessoas não apenas hábeis para fazer coisas, mas pessoas cada vez mais autônomas, um sentido que tinha sido deixado de lado a partir de uma concepção educacional profundamente instrumentalizada.

\section{Referências bibliográficas}

ALTHUSSER, Louis. Aparelhos Ideológicos de Estado. 2. ed. Rio de Janeiro: Edições Graal, 1985.

COQ, Guy. Mounier: o engajamento político. Aparecida, SP: Ideias \& Letras, 2012.

MOUNIER, Emmanuel. O personalismo. São Paulo: Martins Fontes, 1976. . Manifesto ao serviço do personalismo. Lisboa: Moraes, 1967.

Critério, 1956. ¿Qué es el personalismo? Buenos Aires: Ediciones 
LOPEZ, Fernando Vela. Persona, poder, educacion: Una lectura de E. Mounier. Salamanca: Editorial San Esteban, 1989.

LORENZON, Alino. A atualidade do pensamento de Emmanuel Mounier. 2. ed. rev. ampl. Ijui: UNIJUI, 1996.

LUCKESI, Cipriano Carlos. Filosofia da educação. 21. ed. São Paulo: Cortez Editora, 2005.

NOBRE, Marcos. A teoria crítica. Rio de janeiro: Jorge Zahar, 2004.

ROCHA, Acílio da Silva Estanqueiro. Personalismo e Europeísmo: Pessoa, Cultura, Europa, in: José Luís Brandão da Luz. Caminhos do pensamento. Lisboa: Edições Colibri/Universidade dos Açores, 2006.

ROCHA, Antonio Glauton Varela. Emmanuel Mounier: antropologia e filosofia política a serviço da dignidade humana. Jundiaí: Paco Editorial, 2013. 